\title{
Histórias em quadrinhos como recurso pedagógico
}

\section{Comics as a pedagogical resource}

\author{
Taís Conceição dos Santos ${ }^{1}$ | taisquim@hotmail.com \\ Elienae Genésia Corrêa Pereira ${ }^{3}$
}

\section{RESUMO}

Há muito encontramos reflexões acerca da relação entre arte e educação. Neste sentido, o grande potencial educativo das Histórias em Quadrinhos (HQs) para o avanço das Ciências deve ser evidenciado. Este estudo visa identificar os aspectos positivos da inserção de HQs como atividade introdutória e de reflexão para as questões da prática docente com licenciandos em Química no Rio de Janeiro. Os resultados indicaram que o uso de HQs pode ser um instrumento eficiente para fomentar a discussão, incentivando a reflexão por parte dos futuros docentes.

Palavras-chave: Histórias em quadrinhos; Ensino de ciências; Recursos pedagógicos.

\section{ABSTRACT}

Long ago we found reflections on the relationship between art and education. In this sense, the great educational potential of Comics for the development of science teaching must be evidenced. This study aims to identify the positive aspects of the inclusion of Comics as an introductory activity and to propose debates on issues of teaching practice with undergraduate students in Chemistry in Rio de Janeiro. The results indicated that the use of comics could be an effective tool to encourage discussion and reflections by the future teachers.

Key Words: comics; science teaching; pedagogical resources.

1 CEFET/RJ - Centro Federal de Educação Tecnológica Celso Suckow da Fonseca, Rio de Janeiro, RJ.

2 SME - Secretaria Municipal de Educação, Rio de Janeiro, RJ.

3 IOC - Instituto Oswaldo Cruz - FIOCRUZ, Rio de Janeiro, RJ. 


\section{INTRODUÇÃO}

Nas últimas décadas o olhar voltado para as Histórias em Quadrinhos (HQs) tem crescido motivado por inúmeras pesquisas que vêm verificando o potencial educativo e a utilidade desta prática pedagógica, para além de uma aula lúdica (PEREIRA e SANTOS, 2009; SANTOS e PEREIRA, 2011 e 2013). Este fato aponta, cada vez mais, as HQs como uma poderosa ferramenta cognitiva no campo educacional. Dentro deste contexto, Silva (1985, p. 59) ressalta que as HQs "tratam de assuntos os mais diversos, como Matemática, Comunicação e Expressão, Ciências Físicas e Biológicas, História, Moral e Civismo, Religião e outros temas de interesse da escola”, dessa forma as mesmas ganham destaque sendo utilizadas em sala de aula como recurso pedagógico. Além disso, Pizarro (2009) salienta que a literatura na área de Ensino de Ciências aponta de modo consensual a relevância do uso de HQs enquanto recurso didático, e para atestar esta contribuição, já possui uma série de publicações nacionais e internacionais que divulgam as mais diversas experiências realizadas, apoiadas neste recurso.

Atualmente, as HQs vêm adentrando as escolas e salas de aula com relativa facilidade, fato que nem sempre ocorreu. Recentemente, os quadrinhos foram incluídos como gênero de leitura necessário a educação com o apoio do Programa Nacional Biblioteca na Escola (SILVA, 2011). Além disso, o incentivo dado a esta leitura, cuja orientação quanto à maneira de utilização foi explicitada nos Parâmetros Curriculares Nacionais (PCNs), corroborou para o fortalecimento da utilização deste gênero de literatura enquanto recurso pedagógico.

As HQs auxiliam na veiculação de temas específicos a um maior número de pessoas. Isto porque, sua linguagem caracteriza-se por combinar a imagem com o texto escrito, articulando assim temas do cotidiano. É uma literatura marcada pelas ideias da sociedade da época, para atingir um determinado objetivo. Isso sem mencionar que seus textos revelam as mais diversas intenções como: informar, convencer, seduzir, divertir, sugerir estados de ânimo, entre outras (CIRNE, 2000), desta forma formando opiniões e provocando reflexões.

Nota-se, então, a existência de um movimento crescente de estímulo ao uso deste recurso didático em ambientes escolares. Tirinhas e HQs já aparecem em livros didáticos, revistas, concursos públicos e outros processos educativos ou seletivos, caracterizando assim a sua importância enquanto recurso pedagógico. Neste contexto, Caruso e Silveira (2009) ressaltam que a capacidade que têm as HQs de atrair o adolescente ou o leitor jovem está fazendo com que educadores das diversas áreas de conhecimento aproveitem cada vez mais esse instrumento, cuja utilização corrobora com o preconizado na Lei de Diretrizes e Bases (LDB): a valorização de situações do cotidiano e da vivência das crianças e dos jovens.

No entanto, ainda há poucas análises desses materiais no campo educacional (FREITAS, 2008). Assim, esta investigação contribui para o aumento do conhecimento sobre essa ferramenta e suas contribuições para o campo educacional. Neste sentido, este trabalho teve como objetivo identificar os aspectos positivos da inserção do uso de HQs como atividade introdutória com alunos licenciandos na área de Ciências de uma Universidade na cidade do Rio de Janeiro (RJ). Para tal, priorizou uma pedagogia que motivasse a reflexão e discussão por parte dos alunos com as docentes, acerca de algumas questões epistemológicas ligadas a prática educacional.

\section{METODOLOGIA}

Este trabalho foi desenvolvido durante um mini-curso realizado com licenciandos da área de Ciências. O grupo selecionado constituiu-se de onze alunos de uma Universidade Pública localizada no Rio de Janeiro (RJ), sendo os mesmos do $5^{\circ}$ ao $8^{\circ}$ período da graduação, alguns deles, inclusive, já possuindo experiência na área de docência, seja através de estágios ou até mesmo por já atuarem como professores regentes por turmas.

A intervenção pedagógica foi estruturada na reflexão da prática pedagógica e posterior discussão entre os licenciandos e as docentes. Nossa experiência com a utilização dos quadrinhos consubstanciou-se a partir da percepção das pesquisadoras em estimular a reflexão nos alunos motivando a discussão em grupo. 
Dentro da variedade de HQs existentes, foram selecionadas duas tirinhas da Mafalda como potenciais leituras introdutórias para reflexões acerca da importância em aprender Ciências, a relevância de conhecimentos ligados ao contexto socioambiental, o ensino tradicional das Ciências e a utilização na vida cotidiana dos conhecimentos aprendidos na escola. A escolha das HQs da Mafalda está ligada ao fato de a mesma, segundo Bahls e Rezende (2011), caracterizar-se por uma anti-heroína que tem como característica criticar comportamentos e situações questionando a sociedade, opondo-se ao habitual papel dos heróis.

Desta forma, pretende-se que as considerações feitas sobre esta experiência sirvam de ponto de apoio para a reflexão sobre uma maior utilização de atividades lúdicas e artísticas, como as HQs, servindo de suporte educacional e enfocando as relações entre ciência e arte. É necessário salientar que, neste estudo, a metodologia da observação participante esteve presente em todos os momentos, o que proporcionou ao estudo uma visão mais crítica e profunda da realidade escolar dos sujeitos.

\section{RESULTADOS E DISCUSSÃO TEÓRICA}

A fim de iniciar a discussão, as pesquisadoras apresentaram aos licenciandos duas tirinhas da Mafalda de modo a motivá-los a reflexão a respeito de sua prática pedagógica. A primeira tirinha da Mafalda apresentada aos sujeitos tinha por objetivo levá-los a refletir sobre a quantidade de conteúdo ministrado nas aulas de Ciências e sua pertinência na matriz curricular, como observado na Figura 1.
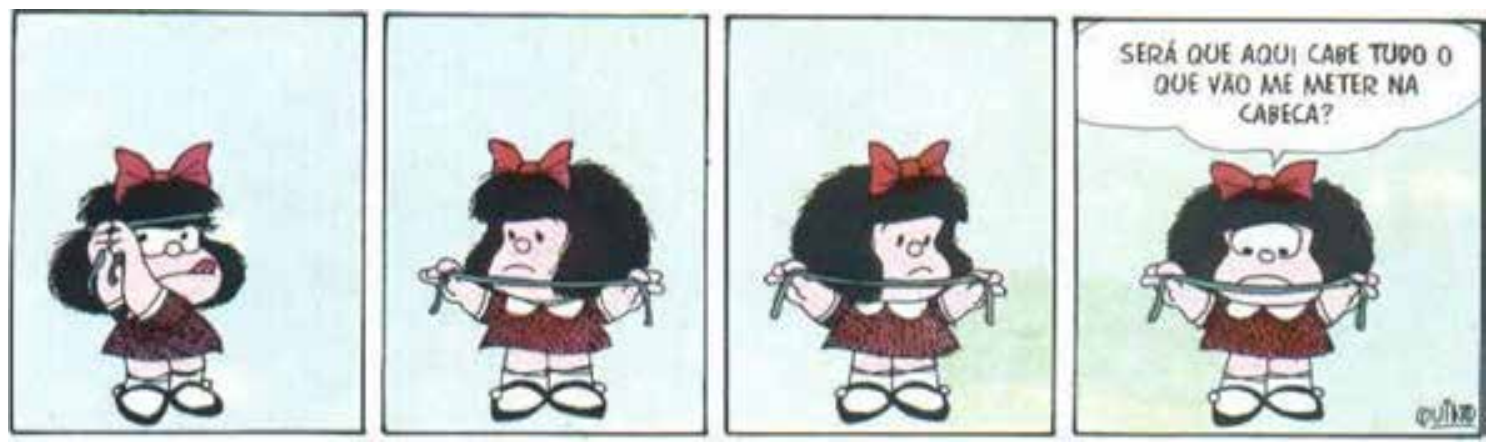

Figura 1: $1^{a}$ HQs usada na atividade

Após a leitura e reflexão da tirinha os licenciandos discutiram a respeito do ensino tradicional de Ciências, muitas vezes reduzido a simples memorização de leis, conceitos e fórmulas. Segundo os sujeitos, na tirinha a personagem Mafalda demonstra a preocupação com o excesso de conteúdos ministrado nas aulas, que neste caso, consideramos como o de Ciências. Além disso, os sujeitos destacaram que, mediante a tamanha carga de conteúdos dos currículos, os alunos não conseguem compreender a importância em aprender Ciências para que exerçam seu papel de cidadão na sociedade. Os licenciandos ressaltaram que, por vezes, o excesso de conteúdos no curto espaço de tempo não permite que os alunos percebam em como tais conhecimentos estão interligados à vida cotidiana dos mesmos e, desta forma, não refletem sobre a importância em aprender Ciências.

Diante de tal fato, os graduandos começaram a discutir da pertinência ou não de todos os conteúdos de Ciências dispostos nas matrizes curriculares, sejam no Ensino Fundamental ou no Ensino Médio, como relatado abaixo:

\footnotetext{
“A gente está tão preocupado em fechar o conteúdo que às vezes até temos vontade de fazer um trabalho que esteja mais ligado ao dia-a-dia do aluno mas fica com medo de não dar tempo no final do ano de dar toda a matéria e aí grande parte das discussões fica na teoria mesmo”
} 
é que damos todo o conteúdo e acaba que o aluno ‘decora’ grande parte dele para fazer as provas e depois esquece tudo e ponto final".

Integrantes do curso - Debate final

Dentro de uma visão de currículo flexível e abrangente, o mesmo deve trabalhar com habilidades que vão além do desenvolvimento cognitivo, envolvendo diferentes campos do saber. Neste sentido, Moreira (2006) enfatiza que é o currículo deve possibilitar ao aluno resolver problemas de sua vida cotidiana, desenvolver habilidades e valores além de romper com a organização disciplinar.

Posteriormente a essa discussão, lhes foi apresentada uma segunda tirinha (Figura 2).
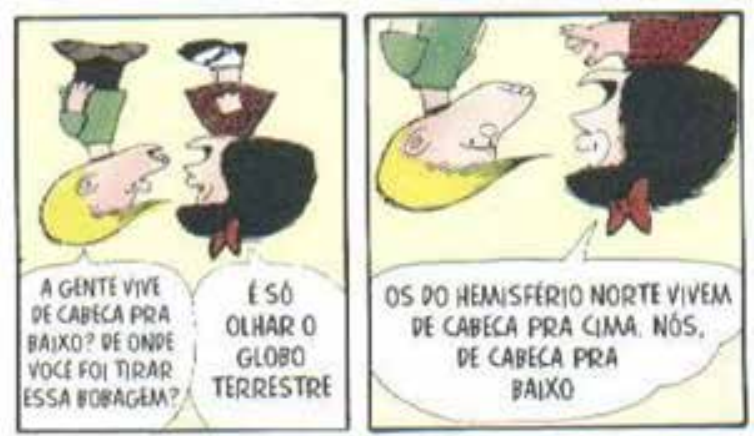

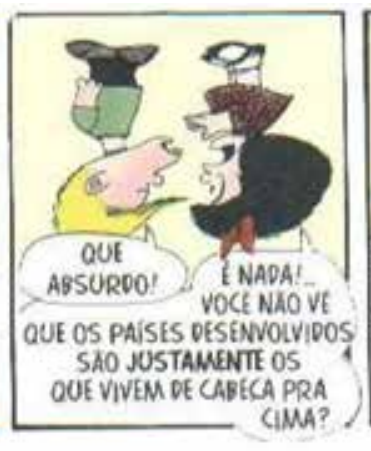

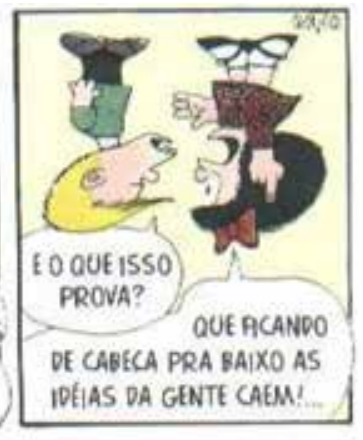

Figura 2: $2^{a}$ HQs usada na atividade

Após a leitura e reflexão desta segunda tirinha, os licenciandos iniciaram uma nova discussão a respeito da utilização dos conhecimentos adquiridos na escola na vida cotidiana. Segundo os graduandos, na tirinha a personagem Mafalda demonstra apenas ter 'decorado' a posição dos países no globo terrestre sem, em momento algum parar para refletir sobre a ligação de tal fato com sua vida, sem uma contextualização. Eles ainda destacaram que, assim como a personagem Mafalda, os alunos por vezes não conseguem compreender a tamanha relevância em estudar alguns tópicos ligados às questões socioambientais e a importância destes assuntos na vida cotidiana.

As discussões geradas durante o curso permitiram uma maior reflexão por parte dos sujeitos, em relação ao uso do recurso pedagógico HQs, como instrumentos facilitadores da introdução de conteúdos nas Ciências. Além disso, as atividades realizadas proporcionaram aos futuros professores um espaço para esclarecimento e reflexão quanto ao trabalho docente e sua formação. Neste contexto, os licenciandos puderam refletir sobre a importância em aprender Ciências, a relevância de conhecimentos ligados ao contexto socioambiental, ao ensino tradicional das Ciências e a utilização dos conhecimentos aprendidos na escola na vida cotidiana, questões estas intrínsecas a prática docente. Frente a este cenário, Reis e Galvão (2005) ressaltam que, a reflexão - sobre a prática - assume um papel determinante no desenvolvimento pessoal e profissional dos professores. A reflexão sobre a prática docente é fundamental na superação de situações problemáticas, permitindo ao professor criticar a sua compreensão inicial do fenômeno e construir uma nova teoria fundamentada na prática, sendo este tipo de reflexão que permite que os professores se assumam como investigadores na prática (e sobre a prática) envolvendo-se num processo contínuo de auto-formação.

Mediante este trabalho foi possível observar que o grupo, constituído por alunos da graduação em licenciatura na área de Ciências, apresentava desconhecimento do uso de HQs enquanto recurso pedagógico, o que, segundo os participantes, era devido ao fato de nunca terem recebido nenhuma orientação para a utilização de tal recurso. Por conta disto, acabavam sempre optando pela utilização de textos tradicionais e do livro didático, desconsiderando o uso dos quadrinhos. Além disso, os mesmos destacaram que mesmo tendo orientação dos PCNs para a utilização das HQs eles não conseguiam vislumbrar como fazer uso de tal recurso de modo crítico e refle- 
xivo. Outro aspecto importante é que os sujeitos também destacaram que o trabalho com as HQs serviria de incentivo à leitura dos alunos e que possibilitaria um trabalho interdisciplinar com outras disciplinas do currículo.

Dentro desta perspectiva, Moreira (2000) sugere a legitimidade da diversidade dos materiais instrucionais em substituição ao livro didático e neste contexto as HQs aparecem como um valioso agente de reelaboração de conhecimentos e construção de competências artísticas, científicas e lingüísticas pelos alunos.

\section{CONCLUSÕES}

A proposta de introduzirmos a leitura das HQs foi aceita pelos licenciandos, muito embora alguns ainda não conhecessem este recurso pedagógico. Contudo, atualmente o professor deve aproximar-se mais da realidade dos alunos para que as aulas sejam motivadoras e instigantes para os mesmos. Neste sentido, as HQS surgem como um interessante recurso pedagógico, buscando uma postura pedagógica que propicie a descoberta do conhecimento, da criatividade e da expressividade do aluno de modo lúdico.

Diante deste contexto, podemos concluir que os sujeitos conseguiram rever seus conceitos enquanto futuros docentes, apontando a necessidade de ampliarem seus conhecimentos e experiências para além da universidade. Entretanto, para as autoras ficou clara a importância da criação de espaços para discussão de práticas e vivências pedagógicas de modo a contribuir para o desenvolvimento de uma proposta de ensino de Ciências inserida na realidade e contextualizadora.

Desta forma, as autoras acreditam ser possível ensinar Ciências fazendo uso das HQs como recurso didático. Em contrapartida, ressaltamos que ainda hoje são poucas as pesquisas com HQs e por vezes ainda prevalece à descrença por parte de muitos docentes neste recurso pedagógico que tanto tem a contribuir no campo do ensino e das Ciências em especial.

\section{REFERÊNCIAS BIBLIOGRÁFICAS}

BAHLS, T. M.; REZENDE, C. C. As tiras em quadrinhos no ensino/aprendizagem de espanhol como língua estrangeira. In: CONGRESSO NACIONAL DE EDUCAÇÃO - EDUCERE, 10, 2011, Curitiba. Anais do X Congresso Nacional de Educação - EDUCERE. Curitiba, 2011, p. 4487-4498.

CARUSO, F.; SILVEIRA, C. Quadrinhos para a cidadania. História, Ciências, Saúde - Manguinhos, v. 16, n. 1, p.217-236, jan-mar, 2009.

CIRNE, M. Quadrinhos, sedução e paixão. Petrópolis, RJ: Vozes, 2000.

FREITAS, D. A. S. O Discurso da Educação Escolar nas Histórias em Quadrinhos do Chico Bento. 2008. $145 f$. Dissertação (Mestrado em Educação) - Universidade Federal de Minas Gerais, Belo Horizonte, MG, 2008.

MOREIRA, M. A. Aprendizaje significativo: teoria y práctica. Madrid: Visor, 2000.

MOREIRA, A. F. B. (org.). Currículo: políticas e práticas. Campinas: Papirus, 2006.

PEREIRA, E. G. C.; SANTOS, T. C. dos. O uso de Oficinas de Histórias em Quadrinhos como instrumento de avaliação no ensino de Ciências. In: SIMPÓSIO EM ENSINO DE CIÊNCIAS E MEIO AMBIENTE DO RIO DE JANEIRO, 1, 2009, Volta Redonda. Anais do I Simpósio em Ensino de Ciências e Meio Ambiente do Rio de Janeiro. Volta Redonda, 2009, p. 75.

PIZARRO, M. V. Histórias Em Quadrinhos e o Ensino De Ciências nas Séries Iniciais: Estabelecendo relações para o Ensino de Conteúdos Curriculares Procedimentais. 2009. 188f. Dissertação (Mestrado em Educação para a Ciência) - Universidade Estadual Paulista “Júlio de Mesquita Filho”, Bauru, SP, 2009. 
REIS, P.; GALVÃO, C. Controvérsias sócio-científicas e práticas pedagógicas de jovens professores. Investigações em Ensino de Ciências, v. 10, n. 2, p. 131 - 160, 2005.

SANTOS, T. C.; PEREIRA, E. G. C. Oficinas de Histórias em Quadrinhos como recurso pedagógico no ensino de Ciências. In: CONGRESO INTERNACIONAL SOBRE INVESTIGACIÓN EN DIDÁCTICA DE LAS CIENCIAS, 9, 2013, set. 9-12, Burgos, Espanha. Trabalho aceito.

O uso de Oficinas de Histórias em Quadrinhos como instrumento de avaliação no ensino de Ciências. In: ENCONTRO NACIONAL DE PESQUISA EM EDUCAÇÃO EM CIÊNCIAS - ENPEC, 8, 2011, Campinas. Anais do VIII Encontro Nacional de Pesquisa em Educação em Ciências - ENPEC. Campinas, 2011.

SILVA, J. N. HQ nos Livros Didáticos. In: LUYTEN, S. M. B. (Org.). História em Quadrinhos: Leitura Crítica. São Paulo: Paulinas, 1985.

SILVA, K. S. As Histórias em Quadrinhos como fator didático-pedagógico: alguns aspectos da sua produção acadêmica entre 1990 e 2002. In: CONGRESSO NACIONAL DE EDUCAÇÃO - EDUCERE, 10, 2011, Curitiba. Anais do X Congresso Nacional de Educação - EDUCERE. Curitiba, 2011, p. 16415-16424. 